\title{
Observações SObre a COMPLETUde do ORDENAMENTO ESTATAL ${ }^{1}$
}

\author{
Santi Romano*
}

\author{
Tradução de Felipe Pante Leme de Campos ${ }^{* *}$
}

\begin{abstract}
$\S 1$. O problema das lacunas do ordenamento jurídico: imprecisão dos termos em que frequentemente se coloca. - $\$ 2$. O problema não concerne às matérias do ordenamento jurídico. $-\$ 3$. e nem tampouco às suas normas. Crítica de outas opiniões. - \$4. Possibilidade de lacunas institucionais. Independência de tais lacunas em relação à existência ou não de regras que as prevejam. - §5. Possibilidade excepcional de lacunas em relação aos sujeitos.
\end{abstract}

1 Tradução do original italiano "Osservazioni Sulla Completezza Dell'ordinamento Statale. (Modena: Facolta di Giurisprudenza della R. Università degli Studi di Modena, 1925)”. Preservou-se, quanto se pôde, a estrutura estilística original do escrito. Santi Romano se utiliza, com frequência, das inversões e dos não menos usuais apostos. Tentou-se manter os termos conforme o original. Apôs-se, quando necessário, nota explicativa, de responsabilidade do ora Tradutor, devidamente identificada como [N. do T.].

* Santi Romano (Palermo, 31 de janeiro de 1875 - Roma, 3 de novembro de 1947). Graduou-se, em 1896, pela Università di Palermo, alma mater na qual tivera como preceptor o juspublicista Vittorio Emanuele Orlando (18601952) e com quem compartilhava "uma formação eminentemente germânica e as referências como von Gierke e, sobretudo, Jellinek em prevalência a Laband e a von Gerber”. Logo após graduar-se, Santi Romano recebe já, em 1898, a livre docência em Direito Administrativo. No ano seguinte, torna-se Professor de Direito Constitucional na Università di Camerino; em 1902, torna-se Professor "straordinario" de Direito Internacional na Università di Modena e, em 1905, assume ali também o Direito Constitucional. Em 1906, torna-se Professor “ordinario". Em 1909, transfere-se para Pisa, quando assume a cátedra de Direito Constitucional, "pronunciando, no início deste ano acadêmico, o célebre discurso inaugural sobre Lo Stato moderno e la sua crisi”. Entre 1917 e 1921, integra o Conselho Superior da Instrução Pública, transferindo-se, em 1924, para Milão; então, na titularidade da Cátedra de Direito Constitucional, na Statale di Milano; torna-se aí, entre 1927-1928, "preside” da Faculdade de Direito. Antes, porém, em 1925, é nomeado para a Comissão dos 'dezoito' ou “dei Soloni”, instituída para elaborar a reforma constitucional. É nomeado Presidente do Consiglio di Stato, onde permanece entre 1929-1944, período a partir do qual, então, transfere-se para Roma, na La Sapienza, e se ocupa de Direito Administrativo e de Ciência da Administração entre 1929-1931, e de Direito Constitucional entre 1932-1942. Vide Aldo Sandulli, "Romano, Santi," in Dizionario Biografico Dei Giuristi Italiani (XII-XX Secolo) / Diretto Da Italo Birocchi [et Al.] (Il Mulino, 2013); Istituto Treccani, "Enciclopedia Treccani Online," n.d., http://www.treccani.it/; Gaetano Armao, "Santi Romano Protagonista Della Scuola Palermitana Di Diritto," Nuove Autonomie 1 (2018): 47-62; Sabino Cassese, “Ipotesi Sulla Formazione de 'L'ordinamento Giuridico' Di Santi Romano,” Quaderni Fiorentini per La Storia Del Pensiero Giuridico Moderno I (1972): 243-83. Os filhos, Silvio Romano (1907-2009), era Professor Emérito de Instituições de Direito Romano na Università di Torino, e o também jurista, Salvatore Romano (1904-1975), que herdara o nome do avô, lecionou Direito Civil na Università di Firenze. É, de Salvatore, o neto de Santi Romano, o também Professor Alberto Romano (1932), emerito di Diritto Amministrativo, na La Sapienza di Roma, a quem se registra o faustoso afeto e gratidão, para além da gentil e disposta pessoa, pelas dúvidas esclarecidas, histórias compartilhadas e, sobretudo, pela cortesia afável em conceder os seus pessoais "ringraziamenti per l'attenzione che dà agli scritti del Nonno".

**Ph.D. em Direito (Teoria e Storia del Diritto) pela Università Degli Studi di Firenze (Florença - Itália). Mestre em Direito (Teoria e História do Direito) pelo Programa de Pós-Graduação em Direito da Universidade Federal de Santa Catarina (UFSC). Graduado em Direito pela Universidade de Fortaleza (UNIFOR). E-mail: <felipe.pantelemedecampos@unifi.it>. https://orcid.org/0000-0002-5194-2554 
§ 1. - Que o Estado, como qualquer outro ordenamento jurídico, tenha uma esfera circunscrita, e, então, de muitas maneiras e em muitos aspectos limitada, é um ponto que, por mais que amiúde desconhecido, salutar se nos mostra ora assumi-lo como pressuposto ${ }^{2}$.

De todo diverso, embora intimamente correlacionado, é o problema de se, na perspectiva interna dessa esfera, que resulta do direito positivo e prescinde então de qualquer valoração "de iure condendo" acerca da correspondência ou não aos princípios da política legislativa, ele seja sempre e necessariamente um ordenamento completo ou se pode, ao contrário, apresentar "lacunas".

Esse problema não pode ser exatamente compreendido e formulado se não se libertá-lo de dois equívocos fundamentais que nele costumam recorrer.

O primeiro deles é que, tendo-se considerado sempre e exclusivamente o ordenamento estatal enquanto um complexo de normas, o problema se referia apenas à completude ou não do sistema normativo com o qual o ordenamento se identificaria. $\mathrm{O}$ segundo deles é consequência direta da opinião errônea conforme a qual o ordenamento, para ser completo, deveria abranger, para provê-las, todas as relações da vida social, todas as ações humanas, seja para ordená-las, seja para proibi-las ou para declará-las lícitas.

De forma que, partindo desses dois pontos de vista inexatos, a questão tenha sido reduzida aos seguintes termos: o direito estatal contém as normas que bastam para regular todas as relações jurídicas? E com esta última expressão tem-se compreendido todas as relações que, pela sua natureza intrínseca mesma, não sejam insuscetíveis de serem juridicamente ordenadas ${ }^{3}$.

Parece-nos que a própria formulação dessa pergunta esteja embebida num critério de direito natural, certamente contra a intenção daqueles que a propuseram, uma vez que se trata de uma questão puramente de direito positivo; visto que, a partir do ponto de vista de um ordenamento jurídico concreto, uma questão, ainda que seja mesmo capaz de ser regulada pelo direito, se não o fosse efetivamente regulamentada pelo direito, não se poderia verdadeiramente sequer mencioná-la como uma questão jurídica.

${ }^{2} \mathrm{O}$ presente texto articula-se com as ideias que desenvolvi no meu trabalho L'ordinamento giuridico, Pisa, 1918, e deste ele constitui uma ulterior abordagem, que pretende desvanecer brevemente a promessa ali feita ( $\$ 47$, p. 183) de reexaminar o problema das lacunas. Isso justifica o carácter fugaz de alguns argumentos sobre os quais já me detive anteriormente e justifica também o fato de que, acerca do problema mencionado ora eu me ocupe apenas a partir daqueles aspectos que interessam diretamente à minha tese fundamental, sobrevoando por sobre os outros demais pontos e sobre as inúmeras teorias que se lhe estão correlacionadas.

3 Nesse sentido, veja-se o que expõe explicitamente Donato Donati, Il Problema Delle Lacune Dell'ordinamento Giuridico (Milano: Società editrice libraria, 1910), pp. 31-32 e, especialmente, p. 81. 
A propósito, já é conhecido que a essa pergunta foi dada uma resposta ora afirmativa, excluindo-se, assim, a existência de lacunas; ora negativa, admitindo-se, então, a possibilidade de lacunas: num e noutro caso, com uma série de argumentos que, dados os descuidos iniciais, não podem ser considerados admissíveis.

$\S 2$. - Antes de qualquer coisa, deve-se observar que o problema não diz respeito a "matérias" que sejam compreendidas ou não na esfera do ordenamento estatal. Porque nenhuma matéria, ou seja, nenhum interesse ou grupo de interesses sociais deve necessariamente, do ponto de vista jurídico, ser levada em consideração pelo Estado, pelo que se segue, sob tal perspectiva, que sobre o seu ordenamento não se pode afirmar sê-lo nem completo nem incompleto.

Em relação aos "ius condendum", poder-se-ão notar as suas eventuais imperfeições, a sua eventual inadequação às necessidades sociais, às exigências da civilização, aos princípios da justiça abstrata.

No entanto, essa reprimenda, que como todas as coisas humanas são sempre aperfeiçoáveis, poderia ser aplicada a todo e a qualquer ordenamento, carece de qualquer sentido quando se permanece no terreno do direito positivo; o qual é aquilo que é: compreende no seu âmbito as matérias que compreende, exclui as demais, sem que jamais se possa apontá-lo, por tal exclusão, incompleto.

Além disso, se uma determinada matéria é por ele considerada tão somente de forma parcial, isso quer dizer que o que aí sobeja é de todo irrelevante juridicamente, o que se nos mostra perfeitamente possível e qualquer outra coisa que não infrequente ${ }^{4}$.

§ 3. - Considerações análogas e de todo subsequentes poderiam ser feitas também no que se refere às normas.

A doutrina que nega a existência de lacunas se regozijou consigo mesma, num pintalgado, para demonstrar que todo ordenamento jurídico deve conter uma norma para cada caso possível, ainda que não o seja regulado direta e especificamente ${ }^{5}$.

Também no direito italiano, corroborando tal suposição, foi invocado, em primeiro lugar, o princípio segundo o qual o juiz, para não ser culpado do crime de negação de justiça, deve decidir todo caso submetido ao seu exame aplicando uma norma jurídica, a qual, por conseguinte, deve necessariamente existir; e, em segundo lugar, o art. 3 das disposições preliminares ao código civil que, na ausência de disposições legais precisas ou de disposições que regulem casos similares ou matérias

\footnotetext{
${ }^{4}$ Veja-se o meu L'ordinamento Giuridico: Studi Sul Concetto, Le Fonti e i Caratteri Del Diritto, ed. Enrico Spoerri (Pisa: Mariotti, 1917), passim e, especialmente, o $\$ 47$.

${ }^{5}$ Para uma revisão dessas opiniões e da bibliografia correlata, remetemos à obra acima mencionada de Donati e aos mais recentes estudos de Brunetti, recolhidos nos seus Scritti Giuridici Varii, vol. 1 (Torino: Unione Tipografico-Editrice Torinese (UTET), 1915), 34 ss.; Scritti Giuridici Varii, vol. 3 (Torino: Unione Tipografico-Editrice Torinese (UTET), 1920), 1 ss., 30 ss., 50 ss.; Scritti Giuridici Varii, vol. 4 (Torino: Unione Tipografico-Editrice Torinese (UTET), 1925), 161 ss.
} 
análogas, impõe que a controvérsia seja decidida de acordo com "os princípios gerais do direito" ${ }^{6}$.

A fim de provar que estes últimos sejam sempre suficientes para alcançar esse fim, tomaram-se diferentes caminhos, mas sobretudo dois.

A doutrina mais antiga sustentou que é possível abstrair-se das disposições particulares do ordenamento jurídico e, por sua "força de expansão lógica", dos princípios básicos que estão implícitos no próprio ordenamento, dos quais essas disposições seriam apenas corolários, e esses princípios poderiam ser generalizados até o ponto em que se fizer necessário para a compreensão do caso em questão.

A doutrina mais moderna, duvidando de tal elasticidade indefinida e da expansividade lógica de tais princípios, crera ter-se deparado com uma concretude a qual, pela sua própria natureza, enlaçaria todos os casos não regulados por normas específicas. Ela seria deduzida, por exclusão e por um argumento "a contrario", da totalidade destas últimas: se as leis, ao preverem casos específicos, estabelecessem para

${ }^{6}$ [N. do T.] As disposizioni sulla pubblicazione, interpretazione ed applicazione delle leggi in generale ao Codice Civile del Regno D'Italia, 1865, não nos parece, ao leitor brasileiro, em nada distante e/ou estranha. Sem incorrermos, porém, numa análise desajustada, registra-se apenas a clareza da disposição específica do art. 3, que prevê: "Na aplicação da lei, não se lha pode atribuir significado outro que não aquele tornado evidente pelo próprio significado das palavras, de acordo com a sua conexão com a intenção do legislador". Sempre que uma controvérsia não puder ser decidida a partir de uma disposição legal específica, far-se-á uso das disposições que regulem casos similares ou matérias/assuntos/questões análogas; se, porém, o caso permanecer duvidoso, decidir-se-á de acordo com os princípios gerais do direito.

No original: "Art. 3 - Nell'applicare la legge non si può attribuirle altro senso che quello fatto palese dal proprio significato delle parole secondo la connessione di esse, e dalla intenzione del legislatore. Qualora una controversia non si possa decidere con una precisa disposizione di legge, si avrà riguardo alle disposizioni che regolano casi simili o materie analoghe: ove il caso rimango tuttavia dubbio, si deciderà secondo $i$ principii generali di diritto." Cfr. Italia, Codice Civile Del Regno d'Italia: Corredato Della Relazione Del Ministro Guardasigilli Fatta a S.M. in Udienza Del 25 Giugno 1865 (Torino \& Firenze: Tipografia eredi Botta \& Tipografia Reale, 1865).

A título ilustrativo, registra-se o sucedâneo Códice civile de 1942, em seu art. 12, que, mantido praticamente intacto o sentido anterior, além de alguma eventual substituição e ou supressão de termos, inclui, após os "princípios gerais do direito" o termo "do ordenamento jurídico do Estado". Nesse sentido, o original: "Art. 12. (Interpretazione della legge). Nell'applicare la legge non si puo' ad essa attribuire altro senso che quello fatto palese dal significato proprio delle parole secondo la connessione di esse, $e$ dalla intenzione del legislatore. Se una controversia non puo' essere decisa con una precisa disposizione, si ha riguardo alle disposizioni che regolano casi simili o materie analoghe; se il caso rimane ancora dubbio, si decide secondo i principi generali dell'ordinamento giuridico dello Stato." Pertinente, a propósito, a crítica posterior especificamente pontuada sobre o Art. 12, por Paolo Grossi, precisamente na nota 16, pgs. 28-29 do seu "Um Direito Sem Estado: A Noção de Autonomia Como Fundamento Da Constituição Jurídica Medieval," Revista Jurídica Da Presidência 21, no. 123 (May 31, 2019): 20, https://doi.org/10.20499/2236-3645.RJP2019v21e123-1902, versão traduzida do original "Un Diritto Senza Stato (La Nozione Di Autonomia Come Fondamento Della Costituzione Giuridica Medievale)," Quaderni Fiorentini per La Storia Del Pensiero Giuridico Moderno 25, no. 1 (1996): 267-84. 
tais casos obrigações dadas, ou seja, dadas limitações, isso significaria que, em todos os demais casos, é desejável que não haja qualquer limitação.

E tal vontade se traduziria em uma norma que não seria meramente negativa, pois se considera que uma norma jurídica, para sê-la, deve conter um comando: ela imporia o dever de abster-se de qualquer ação que pudesse também impor uma limitação não prevista por lei, e, correspondentemente, engendraria o direito de estar livre dessa limitação, constituindo, assim, uma relação jurídica de tal conteúdo.

Essa norma geral de exclusão encerraria, dentro do seu cercado, todas as disposições particulares e tornaria completo o ordenamento jurídico, preenchendo as lacunas necessariamente deixadas por esse último?

Parece-nos que a todos esses argumentos se lhes deva contrapor um outro, que pode ser reduzido a uma formulação assaz simples.

Uma vez que há matérias que são juridicamente irrelevantes, é perfeitamente natural que para elas não existam e que nem sequer devam existir normas jurídicas. Aliás, se invertemos essa proposição, na medida em que essas matérias consistem

${ }^{7}$ A teoria que nega a existência das lacunas confiando nos meios técnicos da interpretação, que poderiam sempre preenchê-las, é a teoria clássica: veja-se, dentre tantos outros: Carlo Francesco Gabba, Teoria Della Retroattività Delle Leggi Esposta (Torino: Unione Tipografico-Editrice Torinese (UTET), 1891), 133; a nota aposta por Carlo Fadda e Paolo Bensa na primeira parte da p. 128 do Bernhard Windscheid, Diritto Delle Pandette: Traduzione Dei Professori Carlo Fadda e Paolo Emilio Bensa, Con Note e Riferimenti Al Diritto Civile Italiano. (Torino: Unione Tipografico-Editrice Torinese (UTET), 1902), 128, nota.; Nicola Coviello, Manuale Di Diritto Civile Italiano - Volume Primo (Parte Generale) (Milano: Società editrice libraria, 1910), §28; Francesco Degni, L'interpretazione Della Legge, 2nd ed. (Napoli: Jovene, 1909), 212.

A existência de uma norma conclusiva do ordenamento jurídico que contemplaria todos os casos não previstos por normas específicas é considerada por vários autores. Alguns a delineiam enquanto uma norma puramente negativa, interpretando de forma de todo imprecisa - vide Emilio Betti, "Metodica e Didattica Del Diritto Secondo Ernst Zitelmann," Rivista Internazionale Di Filosofia Del Diritto 1, no. Gennaio-Marzo (1925): 49-85 - a opinião de Ernst Zitelmann, Lücken Im Recht: Rede, Gehalten Bei Antritt Des Rektorats Der Rheinischen Friedrich-Wilhelms-Universität Zu Bonn Am 18 Oktober 1902 (Leipzig: Duncker \& Humblot, 1903), 17 ss. e talvez também a opinião do Gerhard Anschütz, "Lücken in Den Verfassungs- Und Verwaltungsgesetzen," Verwaltungsarchiv (Band 14), 1906, 315 ss. os quais, porém, admitem as lacunas; outros a delineiam enquanto norma positiva, que concederia uma certa liberdade jurídica nos casos em que as leis não imponham limitações. Essa última formulação foi desenvolvida por Donati, op. cit., p. 28 ss. E assentida por outros: por exemplo, Gustav Radbruch, Grundzüge Der Rechtsphilosophie (Leipzig: Quelle \& Meyer, 1914), 185; Eugenio Di Carlo, Dei Nuovi Metodi Di Interpretazione Del Diritto (Palermo: Stab. E. Priula, 1919), 143 ss. De forma contrária, porém: Alessandro Levi, Contributi Ad Una Teoria Filosofica Dell'ordine Giuridico (Genova: Angelo Fortunato Formiggini, 1914), §32; Francesco Ferrara, Trattato Di Diritto Civile Italiano (Roma: Athenaeum, 1921), 225; Ruggero Luzzatto, R. LUZZATTO, Su l'asserita Completezza Dell'ordinamento Giuridico (Ferrara: Taddei, 1922), 22 ss.; Aldo Checchini, "Storia Della Giurisprudenza e Interpretazione Della Legge," Archivio Giuridico XC, no. 1 (1923): 17 ss.; Giuseppe Maggiore, "L'equità e Il Suo Valore Nel Diritto," Rivista Internazionale Di Filosofia Del Diritto, no. Gennaio-Marzo (1923): 17 ss.; Brunetti, Scritti Giuridici Varii, 1925, 4:199 ss.; Vincenzo Miceli, "La Completezza Dell'ordinamento Giuridico," Rivista Internazionale Di Filosofia Del Diritto 1, no. Gennaio-Marzo (1925): 86-101. 
precisamente em casos para os quais não há normas, a ausência normativa não implica outra coisa senão o fato preciso de se tratarem de relações ou de ações que o ordenamento estatal excluiu da sua esfera; o que, em outros termos, significa que se poderia falar de uma limitação do próprio ordenamento, mas jamais de uma lacuna ${ }^{8}$.

Quando há uma norma, ter-se-á que uma determinada ação será imposta ou proibida ou permitida; na hipótese oposta, a ação não trajará nenhuma dessas três figuras e, portanto, não será sequer lícita e nem tampouco ilícita, ela será juridicamente irrelevante e, enquanto tal, refluirá para a esfera da liberdade, não jurídica, mas apenas de fato ${ }^{9}$.

Ei-las, daí, as várias consequências.

Em primeiro lugar, é descabido invocar a obrigação que o juiz tem, aplicando a lei, de decidir toda questão que lhe seja submetida. Essa obrigação será cumprida mesmo quando ele verificar que uma determinada matéria queda-se fora do ordenamento jurídico e, então, assentado nesse último, declarará inexistentes os direitos ou os deveres que as partes eventualmente afirmem sobre um pressuposto distinto e rechaçará as suas ações ou as suas exceções que nele se esteiem.

Em outros termos, uma valoração jurisdicional é sempre possível, no sentido de que ela será, para aquilo que é juridicamente irrelevante, um juízo jurídico negativo ${ }^{10}$.

Em segundo lugar, quando uma controvérsia não puder ser decidida a partir de uma disposição legal precisa e nem a partir de uma disposição da qual se possa inferir uma analogia, que se deva fazer uso daquele processo de construção de princípios gerais ao qual se refere o art. 3 das disposições preliminares do código civil, nada tem a ver com o problema das lacunas ${ }^{11}$.

${ }^{8}$ Em essência, pelo menos no conceito fundamental, é esta a tese desenvolvida, como é sabido, especialmente por Karl Bergbohm, Jurisprudenz Und Rechtsphilosophie (Leipzig: Duncker \& Humblot, 1892), 371 ss., a qual sempre resiste às inúmeras críticas a que tem sido submetida. Desta também não difere substancialmente a opinião do próprio Zitelmann, op. cit.

${ }^{9}$ Da afirmação de que existem liberdades de fato, decorre logicamente que não se pode admitir um único direito de liberdade que compreenda todas as ações que não são impostas ou não proibidas pelo ordenamento jurídico: em vez disso, existem tantos direitos de liberdade quanto ações que são positivamente consideradas como lícitas, isto é, permitidas. Com isso, modifico a opinião por mim sustentada em outras ocasiões. Sobre a pluralidade dos direitos de liberdade, veja-se, por último, porém com fundamento em argumentos distintos, Francesco Ruffini, Corso Di Diritto Ecclesiastico Italiano: La Libertà Religiosa Come Diritto Pubblico Subiettivo (Torino: Bocca, 1924), 184 e ss.

${ }^{10}$ Substancialmente de acordo, Brunetti, Scritti Giuridici Varii, 1925, 4:209 e ss.

${ }^{11}$ Este não é o lugar para recordar os numerosos escritos, mesmo aqueles recentíssimos, que trataram dos assim chamados "princípios gerais". Basta lembrar de que a existência de lacunas no direito positivo, que podem, no entanto, ser preenchidas pela referência que isso, com a disposição que impõe a referência aos princípios gerais, faria ou ao direito natural ou à natureza das coisas, é uma opinião defendida por muitos: mais recentemente por Calogero Gangi, "Il Problema Delle Lacune Nel Diritto Privato," Archivio Giuridico LXXXIX (1923): 137 e ss., (há outras citações) e Calogero Gangi, Ancora Sul Problema Delle Lacune Nel Diritto Privato (Pavia: Tipografia Cooperativa, 1925). Outros, em contrapartida, viram, nessa alusão, uma norma geral conclusiva do ordenamento jurídico, que, 
Trata-se de um procedimento que é e que quer ser exclusivamente um meio de "interpretação" do direito positivo, que serve para "apurar” esse último e, assim, decidir sobre "casos duvidosos" ou "controversos", ou seja, para preencher as assim chamadas lacunas aparentes, para "encontrar" uma norma que, à primeira vista, falta, mas que na realidade existe.

Caso houvesse uma verdadeira lacuna, o intérprete exorbitaria do seu ofício se ele a preenchesse com uma norma a qual ele não encontrou, mas ali a pusera como se o fosse um legislador.

A verdade é que, quando há um assunto juridicamente irrelevante, quer dizer, não regulado pelo direito, ele não pode senão constatar esse fato, e a essa conclusão ele a alcança seja estribado em uma disposição precisa - que eventualmente a declare como tal aquele assunto -, seja, na ausência de tal disposição precisa, fruindo da argumentação arrimada na “analogia legis”, ou “iuris”, quer dizer, determinando um princípio mais ou menos geral a partir do qual se possa depreender essa irrelevância.

De que natureza venha a ser esse princípio, não é importante aqui investigar mais. Em abstrato, poder-se-ia também admitir que ele se traduza em uma norma conclusiva do ordenamento jurídico que exclua qualquer limitação naqueles casos não contemplados nem por disposições específicas nem por outras disposições que possam vir a ser estendidas por meio da analogia ou, tampouco ainda, por uma miscelânea das primeiras e das segundas a partir da qual se possa derivar uma regra que afirme tal limitação.

Nessa hipótese, de qualquer forma, ter-se-ia uma norma negativa que não criaria uma liberdade jurídica - um direito de liberdade e um dever de abstenção das ações contrárias a essa liberdade -, mas estabeleceria tão somente um limite objetivo do ordenamento, do que resultaria uma simples liberdade de fato, não permitida, e, portanto, nem lícita nem ilícita.

Que uma norma, para ser jurídica, deva ser sempre positiva, criar os deveres e, por correlação, também os direitos, parece ser uma verdadeira prenoção. É verdade, entretanto, que, na realidade, a norma que tem sido hipotetizada não existe como tal, pelo menos não no direito italiano. Tem-se apenas que, para determinadas matérias, não existem normas; e, desse fato, o intérprete deve inferir o princípio - que é um simples princípio lógico de interpretação, não uma norma stricto sensu - de que as matérias são, em si mesmas, juridicamente irrelevantes.

portanto, não teria lacunas; assim, na alusão à natureza dos fatos, Alberto Asquini, "La Natura Dei Fatti Come Fonte Di Diritto," Archivio Giuridico LXXXVI, no. fasc. 2 (1921): p. 145, e, na referência à equidade, Maggiore, "L'equità e Il Suo Valore Nel Diritto." 
No entanto, tem-se ocasionalmente sustentado ${ }^{12}$ que uma verdadeira e inconteste lacuna pode ocorrer naqueles casos que, por um lado, são juridicamente relevantes, porquanto contemplados pelo ordenamento, e que para eles há uma norma, mas que, por outro lado, não são totalmente regulamentadas por ela, no sentido de que algum de seus elementos reste indeterminado por causa da incompletude da vontade legislativa.

Parece-nos, no entanto, que essa hipótese é irreal.

Antes de qualquer outra coisa, tal indeterminação usualmente será tão somente aparente e sanável por meio da técnica interpretativa. No entanto, mesmo quando o fosse real, nada além de duas consequências se poderia dela deduzir: ou que se trata de uma matéria que, apenas em parte, é considerada juridicamente relevante, enquanto em parte, precisamente naquela parte em que a norma não se estende, ela permanece fora da esfera do direito, o que, conforme já asseverado, é perfeitamente admissível, aliás, não infrequente; ou mesmo que a norma que se supõe existente, conquanto incompleta, na realidade, carece de um de seus elementos necessários e integrantes e que, portanto, ela permanece ineficaz, ou seja, não é uma norma verdadeira.

Num e noutro caso, não se poderá falar de uma lacuna verdadeira e real, mas terse-á, sempre e tão somente, uma limitação do ordenamento jurídico.

§ 4. - O problema, entretanto, emerge de maneira totalmente diferente quando se considera não apenas o aspecto normativo, mas também o aspecto institucional que o ordenamento jurídico revela.

Desse ponto de vista, o Estado afigura-se como um edifício, cujas diversas partes não somente estão argamassadas umas às outras, mas são amiúde pressupostas umas pelas outras, de modo tal a se complementarem e a se sustentarem mutuamente. Se, por acaso, uma dessas partes falhar e ela for essencial e necessária para as demais que resistirem, pode-se afirmar, tranquilamente, que o edifício resta como se estivesse mutilado, e, ocasionalmente, até mesmo a ponto de ameaçar causar a sua completa ruína; e então é correto falar da existência de uma sua lacuna ${ }^{13}$.

\footnotetext{
${ }^{12}$ Zitelmann, Lücken Im Recht: Rede, Gehalten Bei Antritt Des Rektorats Der Rheinischen Friedrich-WilhelmsUniversität Zu Bonn Am 18 Oktober 1902, op. cit., p. 27 e ss.; Anschütz, "Lücken in Den VerfassungsUnd Verwaltungsgesetzen" loc cit. Andreas von Tuhr, Der Allgemeine Teil Des Deutschen Bürgerlichen Rechts (Leipzig: Duncker \& Humblot, 1910); Roberto De Ruggiero, Istituzioni Di Diritto Civile (Napoli: Alvano, 1921), 156.Zitelmann, Lücken Im Recht: Rede, Gehalten Bei Antritt Des Rektorats Der Rheinischen Friedrich-Wilhelms-Universität Zu Bonn Am 18 Oktober 1902, op. cit., p. 27 e ss.; Anschütz, "Lücken in Den Verfassungs- Und Verwaltungsgesetzen" loc cit. Tuhr, Der Allgemeine Teil Des Deutschen Bürgerlichen Rechts, 41; De Ruggiero, Istituzioni Di Diritto Civile, 156 e ss.

${ }^{13}$ [N. do T.] Acerca da comparação realizada por Santi Romano, no sentido de ruptura estrutural do edifício Estado, salutar registrar que não se trata tão somente de 'lacuna normativa', mas da possibilidade de -diante de tais lacunas - ocorrer um preenchimento político tendente a causar a ruína do Estado como um todo. Nesse sentido, veja-se o seu Lo Stato Moderno e La Sua Crisi: Discorso per l'inaugurazione Dell'anno Accademico Nella R. Università Di Pisa., 1st ed. (Pisa: Tipografia Vannucchi, 1909), especialmente as pgs. 35-36 da versão traduzida como Santi Romano and Felipe Pante Leme de

347 - R. Opin. Jur., Fortaleza, ano 19, n. 32, p.340-353, set./dez. 2021
} 
Assim o é, por exemplo, quando, em um Estado monárquico, extingue-se a dinastia reinante, até o momento em que a Coroa não seja entregue a um novo titular ou até que ela não seja substituída por uma outra instituição que modifique a forma de governo; assim também o é quando, por uma razão qualquer, como uma abstenção mais ou menos persistente do corpo eleitoral, não se constitua nenhuma Câmara eletiva em um Estado que a elenque dentre os seus órgãos constitucionais; e os exemplos poderiam ser prontamente multiplicados.

Em todos esses casos, muitas outras instituições, que não podem funcionar a não ser em sinergia com aquelas que venham a faltar, vivenciam evidentemente uma crise, justamente porque essa falta sim é uma verdadeira lacuna do ordenamento jurídico, que, dentre outras coisas, produz uma interrupção no exercício dos poderes que são, em maior ou menor medida, essenciais ao Estado; e essa interrupção, ao contrário do que pode acontecer em casos determinados, isto é, quando o são previstos e regulamentados, pode ainda ser contrária ao ordenamento que pressuponha que ela jamais ocorra.

A diferença substancial existente entre essas hipóteses e aquela outra, em que apenas uma norma ou um grupo de normas carece, é a seguinte: as instituições podem cessar não apenas por uma causa jurídica, por uma mutação no direito desejada pelo próprio ordenamento, mas também por causas de fato - não importa se necessárias ou voluntárias, ilícitas ou, seja como for, não proibidas -; eis então evidente que a cessação, até que não seja remediada, engendra uma incompletude do ordenamento.

Ela é determinada pela antítese que se estabelece entre o ordenamento tal qual ele subsista na realidade e o próprio ordenamento tal qual deveria sê-lo devido a uma exigência postulada, não em abstrato e de iure condendo, mas a partir da sua própria estrutura concreta e positiva, uma exigência que pode ainda perdurar, não só de fato, mas para o direito não harmonizado com o novo estado das coisas.

As normas, por outro lado - a menos que não cessem devido à derrocada de uma instituição, caso em que tornamos à hipótese anterior - cessam devido a uma mutação do próprio ordenamento que é ela própria jurídica, na medida em que são revogadas por normas posteriores, e, então, ter-se-á um ordenamento de todo novo e diverso, que deve ser considerado em si mesmo e per se, sem que haja qualquer razão para compará-lo com o ordenamento antigo.

$\mathrm{Na}$ ausência dessa comparação, entende-se que não se lhe pode referir a qualificação de completo ou de incompleto, que é sempre um predicado de relação ${ }^{14}$.

Campos, "O Estado Moderno e a Sua Crise," Revista Brasileira de Estudos Políticos 122 (July 13, 2021): 13-44, https://doi.org/10.9732/2021.V122.886.

${ }^{14}$ Parece-nos que assim demonstramos que a conhecida doutrina de Brunetti, Scritti cit., Scritti cit., segundo a qual o ordenamento jurídico, quando considerado em si mesmo, não pode ser considerado nem completo nem incompleto, pois isso seria um julgamento de relação, que é excluído pela própria forma como o problema se coloca - qualquer que seja a apreciação da doutrina em si quando o 
E aqui se faz necessário um aviso. Por aqueles que, nos casos acima conjecturados ou em outros semelhantes, foram enxergadas lacunas do ordenamento jurídico, essas lacunas têm sido relacionadas à falta de normas que ofereçam uma solução jurídica para a anormalidade da situação que se estabelece; que se, por outro lado, uma norma que preveja o caso e preordene um remédio jurídico existe, então não se verificaria mais uma lacuna.

Assim, por exemplo, na hipótese da extinção da dinastia, estabeleceu-se uma distinção entre aquelas constituições que, como a nossa, não pensaram em ditar as disposições para tal evento, e aquelas outras que, diversamente, estabelecem exatamente aquilo que, no caso de tal evento vir a ocorrer, dever-se-á ou poder-se-á realizar para reconstruir o sistema institucional. As primeiras teriam uma lacuna; as demais, por sua vez, seriam completas.

É claro, porém, que, se tal raciocínio estivesse correto, a lacuna consistiria sempre na ausência de normas, o que seria contrário a tudo quanto se tem observado acerca da impossibilidade, até mesmo lógica, de tais lacunas.

A verdade é que, do ponto de vista normativo, o ordenamento jurídico não será, sequer neste caso, incompleto: se há a falta daquela norma, isso quer dizer tão somente que há uma determinada matéria que resta fora dele, que as ações que poderão ser empreendidas por quem quer que seja para instaurar uma nova dinastia, para se chegar a um regime republicano, para estabelecer, em uma palavra, qualquer governo, não deverão ser consideradas nem como impostas, nem proibidas, nem tampouco permitidas, mas tão somente enquanto juridicamente indiferentes, ou seja, em outros termos, ter-se-á - como em outros eventos - uma instauração de fato, não jurídica, de um novo ordenamento constitucional.

Poder-se-á lamentar que o direito positivo tenha-se abstido de ditar disposições acerca dessa matéria, abandonando-a ao jogo das forças políticas e às incertezas que daí decorrem; mas, em todo caso, essa sua imperfeição "de iure condendo" - que, afinal de contas, poderia, às vezes, justificar-se com bons motivos de oportunidade, uma vez que nem sempre convém regular aquilo que presumivelmente só poderá acontecer num futuro longínquo - não autoriza a afirmar que exista ali uma lacuna "de iure condito", que é aquilo que é, seja por esquecimento do legislador, seja por uma sua intenção consciente.

Em contrapartida, do ponto de vista institucional, a lacuna existe se o ordenamento permanece desprovido de uma sua parte integrante, que continua a ser juridicamente necessária para ele. E - observe-se bem - há a lacuna mesmo quando

ordenamento jurídico é considerado como um sistema de - não pode se referir ao próprio ordenamento na medida em que é um sistema de instituições. 
existe uma norma para remediá-la, até quando aqueles que detêm o poder, com base em tal, não provejam efetivamente a reintegrar ou a substituir a instituição caída.

Não é, de fato, a mera existência dessa norma que pode fazer as vezes da instituição cuja falta produz a lacuna: para que esta desapareça, é necessário que a instituição seja ressuscitada ou que as demais se modifiquem de modo tal que possam prescindir da primeira.

Da mesma forma, um edifício que está parcialmente deteriorado permanece deteriorado, ainda que se disponha de um projeto para a sua restauração e até o momento em que essa restauração não seja de fato concretizada. Aliás, a existência daquela norma, como, para continuar na analogia, a existência de um plano de reconstrução, não faz senão atestar explicitamente que há uma lacuna ou que há uma deterioração: a remediabilidade jurídica da primeira não exclui, mas confirma a lacuna mesma de uma forma inequívoca, que resta, então, oficialmente e através de uma norma especial, constatada e declarada.

Se isto é verdade, eis, pois, a prova acerca da exatidão da observação de que o problema das lacunas do ordenamento jurídico se põe de forma distinta, a depender da forma como se lhe considere: como um sistema de normas ou como um sistema institucional; dois pontos de vista que não se excluem e que, aliás, se integram, mas que são diversos, e que, portanto, exigem soluções também diversas.

E, ao mesmo tempo, a impossibilidade de reduzir tudo no ordenamento jurídico ao aspecto normativo também é demonstrada mais adiante.

Uma intuição distante e não comprovada da necessidade de fazer a distinção que tem sido apontada foi a dos escritores que admitiram, embora partindo de pontos de vista diferentes, a possibilidade de lacunas apenas no direito constitucional ou público, negando-as, em vez disso, nos outros campos do direito.

$\mathrm{Na}$ verdade, nem mesmo no direito constitucional, enquanto complexo de normas, podem-se verificar as lacunas; e, diversamente, essas lacunas podem ser observadas mesmo lá onde existam instituições não constitucionais que desapareçam ou que se eclipsem, enquanto sejam juridicamente necessárias para as demais instituições que subsistam.

Verdadeiro é apenas o fato de que o direito constitucional é aquela parte do ordenamento em que o aspecto institucional é de uma importância pujante e no qual é praticamente mais fácil que se produzam aquelas crises que originam as assim chamadas lacunas.

§ 5. - Uma última observação a ser feita é aquela que toca àqueles elementos do ordenamento que são os seus sujeitos. 
Estes, normalmente, quando são considerados singularmente, são elementos não necessários e praticamente fungíveis, de modo que o desaparecimento de um ou de vários deles não pode determinar nenhuma lacuna no ordenamento jurídico mesmo.

Todavia, se esta é a regra, pode ocorrer a exceção. Assim, no caso em que se extingue a família reinante, em última análise, é a ausência de uma pessoa - a pessoa do Monarca - que produz o esfacelamento de uma instituição - a Coroa -, e, então, a lacuna do ordenamento. Contudo, uma vez que isso resulta em uma lacuna institucional, pode-se também prescindir de tomar em consideração imediatamente a primeira causa da qual ela deriva e torná-la uma figura de lacuna em si mesma.

Noutros ordenamentos, porém, especialmente aqueles de tipo antigo, em que exista um governo pessoal e não institucional, o simples fenecer de uma pessoa específica, a quem o ordenamento jurídico atribua, de forma precisa e insubstituível, o exercício necessário dos poderes públicos, pode implicar uma lacuna, análoga à institucional, mas, no entanto, diversa.

\section{REFERÊNCIAS}

ANSCHÜTZ, Gerhard. Lücken in Den Verfassungs- Und Verwaltungsgesetzen. Verwaltungsarchiv (Band 14), 1906.

ARMAO, Gaetano. Santi Romano Protagonista Della Scuola Palermitana Di Diritto. Nuove Autonomie, p. 47-62, 2018.

ASQUINI, Alberto. La Natura Dei Fatti Come Fonte Di Diritto. Archivio Giuridico, v. 86, no. fasc. 2, p. 129-47, 1921.

BERGBOHM, Karl. Jurisprudenz Und Rechtsphilosophie. Leipzig: Duncker \& Humblot, 1892.

BETTI, Emilio. Metodica e Didattica Del Diritto Secondo Ernst Zitelmann. Rivista Internazionale Di Filosofia Del Diritto, p. 49-85, genn./mar. 1925.

BRUNETTI, Giovanni. Scritti Giuridici Varii. Torino: Unione Tipografico-Editrice Torinese (UTET), 1915. v. 1.

BRUNETTI, Giovanni. Scritti Giuridici Varii. Torino: Unione Tipografico-Editrice Torinese (UTET), 1920. v. 3.

BRUNETTI, Giovanni. Scritti Giuridici Varii. Torino: Unione Tipografico-Editrice Torinese (UTET), 1925. v. 4.

CARLO, Eugenio Di. Dei Nuovi Metodi Di Interpretazione Del Diritto. Palermo: Stab. E. Priula, 1919. 
CASSESE, Sabino. Ipotesi Sulla Formazione de 'L'ordinamento Giuridico' Di Santi Romano. Quaderni Fiorentini per La Storia Del Pensiero Giuridico Moderno, p. 243-283, 1972.

CHECCHINI, Aldo. Storia Della Giurisprudenza e Interpretazione Della Legge. Archivio Giuridico XC, no. 1, p. 167-230, 1923.

COVIELlO, Nicola. Manuale Di Diritto Civile Italiano: volume primo (parte generale). Milano: Società editrice libraria, 1910.

DEGNI, Francesco. L’interpretazione Della Legge. 2nd ed. Napoli: Jovene, 1909.

DONATI, Donato. Il Problema Delle Lacune Dell'ordinamento Giuridico. Milano: Società editrice libraria, 1910.

FERRARA, Francesco. Trattato Di Diritto Civile Italiano. Roma: Athenaeum, 1921.

GABBA, Carlo Francesco. Teoria Della Retroattività Delle Leggi Esposta. Torino: Unione Tipografico-Editrice Torinese (UTET), 1891.

GANGI, Calogero. Ancora Sul Problema Delle Lacune Nel Diritto Privato. Pavia: Tipografia Cooperativa, 1925.

GANGI, Calogero. Il Problema Delle Lacune Nel Diritto Privato. Archivio Giuridico, v. 89, p. 137 e ss., 1923.

GROSSI, Paolo. Um Direito Sem Estado: A Noção de Autonomia Como Fundamento Da Constituição Jurídica Medieval. Tradução de Felipe Pante Leme de Campos. Revista Jurídica Da Presidência, v. 21, no. 123, 2019. https://doi.org/10.20499/22363645.RJP2019v21e123-1902.

GROSSI, Paolo. Un Diritto Senza Stato (La Nozione Di Autonomia Come Fondamento Della Costituzione Giuridica Medievale). Quaderni Fiorentini per La Storia Del Pensiero Giuridico Moderno, v. 25, no. 1 (1996): p. 267-84.

ITALIA. Codice Civile Del Regno d'Italia: Corredato Della Relazione Del Ministro Guardasigilli Fatta a S.M. in Udienza Del 25 Giugno 1865. Torino \& Firenze: Tipografia eredi Botta \& Tipografia Reale, 1865.

LEVI, Alessandro. Contributi Ad Una Teoria Filosofica Dell'ordine Giuridico. Genova: Angelo Fortunato Formiggini, 1914.

LUZZATTO, Ruggero. R. LUZZATTO, Su l'asserita Completezza Dell'ordinamento Giuridico. Ferrara: Taddei, 1922.

MAGGIORE, Giuseppe. L'equità e Il Suo Valore Nel Diritto. Rivista Internazionale Di Filosofia Del Diritto, 256-287, genn./mar. 1923. 
MICELI, Vincenzo. La Completezza Dell'ordinamento Giuridico. Rivista Internazionale Di Filosofia Del Diritto, v. 1, p. 86-101, genn./mar. 1925.

RADBRUCH, Gustav. Grundzüge Der Rechtsphilosophie. Leipzig: Quelle \& Meyer, 1914.

ROMANO, Santi. L'ordinamento Giuridico: Studi Sul Concetto, Le Fonti e i Caratteri Del Diritto. Edited by Enrico Spoerri. Pisa: Mariotti, 1917.

ROMANO, Santi. Lo Stato Moderno e la sua crisi. Discorso per l'inaugurazione Dell'anno Accademico Nella R. Università Di Pisa., 1st ed. Pisa: Tipografia Vannucchi, 1909.

ROMANO, Santi. Osservazioni Sulla Completezza Dell'ordinamento Statale. Modena: Facolta di Giurisprudenza della R. Università degli Studi di Modena, 1925.

ROMANO, Santi. O Estado Moderno e a sua crise. Tradução de Felipe Pante Leme de Campos. Revista Brasileira de Estudos Políticos, v. 122, p. 13-44, 2021. https://doi.org/10.9732/2021.V122.886.

RUFFINI, Francesco. Corso Di Diritto Ecclesiastico Italiano: La Libertà Religiosa Come Diritto Pubblico Subiettivo. Torino: Bocca, 1924.

RUGGIERO, Roberto De. Istituzioni Di Diritto Civile. Napoli: Alvano, 1921.

SANDULLI, Aldo. Romano, Santi. In: BIROCCHI, Italo et al. Dizionario Biografico Dei Giuristi Italiani (XII-XX Secolo). Bologna: Il Mulino, 2013.

TRECCANI, Istituto. Enciclopedia Treccani Online. Disponível em: http://www.treccani.it/.

TUHR, Andreas von. Der Allgemeine Teil Des Deutschen Bürgerlichen Rechts. Leipzig: Duncker \& Humblot, 1910.

WINDSCHEID, Bernhard. Diritto Delle Pandette: Traduzione Dei Professori Carlo Fadda e Paolo Emilio Bensa, Con Note e Riferimenti Al Diritto Civile Italiano. Torino: Unione TIPOGRAFICO-EDITRICE TORINESE (UTET), 1902.

ZITELMANN, Ernst. Lücken Im Recht: Rede, Gehalten Bei Antritt Des Rektorats Der Rheinischen Friedrich-Wilhelms-Universität Zu Bonn Am 18 Oktober 1902. Leipzig: Duncker \& Humblot, 1903.

Como citar este documento:

ROMANO, Santi. Observações sobre a completude do ordenamento estatal. Tradução Felipe Pante Leme de Campos. Revista Opinião Jurídica, Fortaleza, v. 19, n. 32, p. 340-353, set./dez. 2021. Título original: Osservazioni Sulla Completezza Dell'ordinamento Statale. 